\title{
'DES’ENTRAVES NO PROCESSO DE AVALIAÇÃO EM MATEMÁTICA
}

Mariluse Santana dos Santos ${ }^{1}$

Alexsandra dos Santos Jesus ${ }^{2}$

\section{RESUMO}

Este artigo discorre sobre os des'entraves no processo de avaliação em matemática que é um dos entraves presentes na prática docente, devido a ausência de resultados positivos $\mathrm{Na}$ ação de ensino aprendizagem, a avaliação é um sistema sucessivo de verificação, que proporciona apoio e colabora para a aquisição de resultados. Diante do objeto proposto a metodologia para investigação do processo de avaliação em matemática foi a pesquisa bibliográfica em livros e artigos. Concluise que a avaliação matemática deve ser planejada como uma possibilidade de alavancar a aprendizagem e incluir os sujeitos através da validação dos seus saberes para a ampliação dos mesmos, apresentando propostas de instrumentos e práticas avaliativas dinâmicas para promover a eficácia nos resultados exitosos na aprendizagem de matemática.

Palavras Chaves: Práticas avaliativas. Matemática. Entraves. Aprendizagem

\begin{abstract}
This article discusses the obstacles in the evaluation process in mathematics, which is one of the obstacles present in teaching practice, due to the absence of positive results. In the action of teaching learning, evaluation is a successive system of verification, which provides support and collaborates. for the acquisition of results. In view of the proposed object, the methodology for investigating the mathematical evaluation process was bibliographic research in books and articles. It is concluded that the mathematical evaluation should be planned as a possibility to leverage learning and include the subjects through the validation of their knowledge for their expansion, presenting proposals for dynamic assessment tools and practices to promote the effectiveness of successful learning results of math.
\end{abstract}

Keywords: Evaluative practices. Mathematics. Barriers. Learning

1 Mestra em Ciências da Educação pela FICS; Especialista em Arte Educação pela Faculdade Afonso Claudio; Especialista em Alfabetização e Letramento pela Como Educare; Licenciada em Normal Superior e Pedagogia pela UNIJORGE; Docente na Prefeitura de Camaçari/BA. Email:marilusesantos@yahoo.com.br.

2 Mestra em Ciências da Educação pela FICS; Especialista em Gestão Escolar com ênfase em Coordenação Pedagógica pela Montenegro; Especialista em psicopedagogia Escolar e Clinica pela FAVIX; Especialista em Alfabetização e Letramento pela FBB; Licenciada em pedagogia pela FAMEC; Docente na Prefeitura de Camaçari/BA.Email:alexsandradsj@gmail.com. 


\section{Introdução}

A matemática é uma ferramenta essencial na solução de vários tipos de problemas, desde quando os homens utilizavam pedras e gravetos para registrar quantidades até os elaborados processos tecnológicos da contemporaneidade, por isso, o ensino da referida disciplina precisa acompanhar as mudanças ocorridas ao longo da história. O ensino de matemática deve ser pautado em práticas inclusivas, que reflitam uma forma de ensino contemporâneo, valorizando a conexão entre os estudos e a vida cotidiana. No momento que desvincula a matéria de sua funcionalidade, desfavorece o interesse dos estudantes por matemática, pois:

O ensino de Matemática é importante também pelos elementos enriquecedores do pensamento matemático na formação intelectual do aluno, seja pela exatidão do pensamento lógico-demonstrativo que ela exibe, seja pelo exercício criativo da intuição, da imaginação e dos raciocínios indutivos e dedutivos (SOUZA, 2001, p. 27).

A matemática é uma linguagem humana, aperfeiçoada culturalmente, formal e precisa, que fornece instrumentos eficazes para a compreensão e atuação na sociedade. Os enganos com relação aos princípios norteadores e às ideias básicas da matemática por parte dos profissionais da educação, quase sempre fruto de experiências pessoais negativas e de uma formação inadequada, são apontados como causas dos problemas educacionais matemáticos.

A partir dessa reflexão, pode-se enfatizar a grande importância do papel do educador em mediar e propor atividades que propiciem aos estudantes a construção de saberes de forma contextualizada, valorizando o fazer matemático presente em seu âmbito cultural. Dessa forma, o trabalho do educador torna-se enriquecedor e expressivo, possibilitando a conexão entre a disciplina de matemática e outras áreas do conhecimento.

O ensino inadequado, as dificuldades de aprendizagem,e a os instrumentos utilizados para aferição do conhecimento constatam que o nível de aprendizagem matemática dos estudantes está muito abaixo do esperado. A não valorização do conhecimento prévio, abordagem, métodos e seleção de conteúdo, a realidade da clientela assim como a falta de associação com outras áreas servem para engrossar o rol das deficiências no ensino da matemática, uma vez que:

Os métodos de ensino e o currículo escolar devem atender ás necessidades dos alunos, estando de acordo com a realidade por eles vivida. A disciplina 
pode estar mais ligada a questões do cotidiano para que possa fazer sentido ao aluno e este se sinta mais motivado em aprender e lidar com problemas enfrentados habitualmente (ALMEIDA, 2006, p. 10).

A matemática deve ser trabalhada de forma significativa para ter sentido a vida dos alunos, contribuindo para aquisição dos conhecimentos apresentados que ao final resultará no sucesso de suas aprendizagens.

A Matemática é uma disciplina muito importante no currículo escolar e pode ser trabalhada de maneira desafiadora e interessante tanto no momento de ministrar as aulas quanto no momento de avaliar os conteúdos da mesma.

\title{
Breve Reflexão Sobre o Ensino de Matemática
}

Ao observar a história da humanidade, pode-se perceber que a Matemática sempre esteve presente na vida do homem, de modo a ajudá-lo a adaptar-se ao meio ou para resolver os mais diversos tipos de problemas, pois:

\begin{abstract}
Ele dividia a presa em partes iguais, com o que criou as frações; cortava com a sua clava ou media um pedaço de pele - comparando comprimentos, admitindo assim as idéias contrárias de 'maior' e 'menor'. Para encurtar o caminho na curva de um rio ele abria um atalho retilíneo através do capim da estepe - junto ao leito dos rios - e com isso traçava a primeira corda de um arco. Fabricava vasos, que eram seus padrões de medida, efetuando assim as primeiras determinações de volume [...]. (KARLSON, 1961, p.3).
\end{abstract}

A Matemática surge com a necessidade humana de contar, calcular, medir, organizar o espaço e as formas e desenvolveu-se a partir da evolução dos povos antigos. Na contramão dessa proposta, alguns educadores ao ensinar matemática, contrários à contextualização, ignoram as culturas, as dificuldades e o tempo de aprendizagem dos diferentes sujeitos.

Outros docentes ensinam apenas métodos com aplicações de fórmulas, não demostrando as relações entre a teoria e a prática, sem trabalhar a importância dos saberes vivenciado por esses sujeitos (TOLEDO, 2009). A ciência matemática tem sido aclamada como um dos conhecimentos mais importantes, dominados por uma minoria privilegiada dotado de raciocínio lógico.

A Matemática caracteriza-se pela abstração, precisão, rigor lógico, conclusões irrefutáveis e vasto campo de aplicação, fornecendo subsídios importantes para áreas do conhecimento como Sociologia, Psicologia, Antropologia, Medicina, Economia Política dentre outras. Na vida diária, a indústria, o comércio e as mais diversas tecnologias não se sustentariam sem a matemática. Esta também é 
considerada uma linguagem por conter signos e significados próprios que sintetizaram as necessidades e o desenvolvimento humano ao longo da trajetória da espécie. O conhecimento matemático se dá em um processo que envolve imaginação, contraexemplos, conjecturas, críticas, erros e acertos.

\section{O Ensino da Matemática e a Legislação}

Atualmente, o grande desafio do ensino da matemática está em adequar o processo educacional às demandas da sociedade heterogênea, em ascensão tecnológica e em constante crescimento. O fazer matemático está insertado no cotidiano do fazer humano, ao comprar, procurar um endereço ou repartir uma jarra de suco, logo, não é uma exclusividade de seres dotados com capacidades superiores. Especificamente, em relação à educação, a Lei de Diretrizes e Bases da Educação Nacional - LDB 9394/96, de 20 de dezembro de 1996, em seu Art. 1ํ, diz:

\footnotetext{
A educação abrange os processos formativos que se desenvolvem na vida familiar, na convivência humana, no trabalho, nas instituições de ensino e pesquisa, nos movimentos sociais e organizações da sociedade civil e nas manifestações culturais (BRASIL, 1998, p. 15).
}

No entanto, a Educação Matemática, tornou-se uma matéria extremamente teórica, de difícil entendimento, devido ao alto grau de abstração e à falta de relações com as práticas diárias. Matéria plenamente acessível aos "seres superiores" com direitos a professores com "status" de gênio.

A consequência negativa do ensino tradicional da matemática alcançou a grande parte das pessoas comuns, que na maioria das vezes, demonstram desinteresse e muitas vezes repulsa pela matéria. Em decorrência desse panorama tornou necessária uma urgente mudança paradigmática do ensino de matemática, e esta busca continua até os dias atuais, pois "o educador deve acreditar que o conhecimento é construído e que ensinar é um processo indissociável do aprender" (FREIRE, 2011, p.24).

Esse movimento no Brasil foi fortalecido com o surgimento, em 1997, do Parâmetro Curricular Nacional (PCN). As informações contidas neste documento foram consideradas necessárias para transformações pontuais e pertinentes em relação a concepções, a aprendizagens e um excelente referencial para a reflexão e prática do ensino da matemática. 
O ensino da matemática, por muito tempo, esteve centrado na própria matemática, em seus conteúdos, sem conexão com outros campos do saber, mas "a sociedade está passando por grandes transformações, com profundos reflexos na educação" (D’AMBROSIO, 2005, p.3). Algumas escolas já desenvolvem projetos que estabelecem conexões da Matemática com outras áreas, inclusive com os temas transversais.

$\mathrm{Na}$ ética, por exemplo, a Matemática permiti que os estudantes valorizem a interação, a troca, a complementação e a dependência entre as pessoas. Em relação ao meio ambiente, a quantificação, os conceitos e os procedimentos matemáticos ajudam na compreensão dos fenômenos naturais, assim como o que podem fazer para contribuir para a preservação das riquezas naturais e da saúde.

O ensino moderno nacional está pautado na Base Nacional Curricular Comum (BNCC), documento que norteia o currículo que deve ser construído e executado em cada unidade escolar do vasto território brasileiro, com espaço para adequações, que podem e devem ser congruente com as diversas realidades, regionais, sociais e econômicas dos educandos deste país. Tal fato influencia a forma e principalmente os objetivos do ensino, que estão alicerçados no desenvolvimento integral do homem enquanto ser social capaz de modificar o ambiente e a realidade em que está inserido.

A Base Nacional Curricular Comum (BNCC) reorganizou o ensino do de matemática em Áreas: Números, Álgebra, Geometria, Grandezas e Medidas e Probabilidade e Estatística, para cada uma destas áreas tem objetivos de conhecimentos e habilidades a serem desenvolvidas.

Para alcançar os objetivos propostos, o professor deve realizar uma abordagem que permita aos estudantes a identificação das principais características dessa ciência, a origem, os métodos, as ramificações e as aplicações na vida; o conhecimento da própria história, seus conhecimentos informais, suas condições sociológicas e culturais

\section{O Programa Etnomatemática}

O entendimento da importância de aspectos sociais, antropológicos e linguísticos na aprendizagem da matemática fomentou novas discussões que 
influenciaram mundialmente as reformas do ensino da Matemática. Dentre as mudanças, destaca-se o Programa Etnomatemática que:

\begin{abstract}
Contrapõe-se às orientações que desconsideram qualquer relacionamento mais íntimo da Matemática com aspectos socioculturais e políticos - o que a mantém intocável por fatores outros a não ser sua própria dinâmica interna. Do ponto de vista educacional, procura entender os processos de pensamento, os modos de explicar, de entender e de atuar na realidade, dentro do contexto cultural do próprio indivíduo. A Etnomatemática procura partir da realidade e chegar à ação pedagógica de maneira natural, mediante um enfoque cognitivo com forte fundamentação cultural (BRASIL, 1997, p.17)
\end{abstract}

A Etnomatemática valoriza as referências matemáticas dos diversos grupos sociais, possibilitando a utilização de alternativas sobressalentes para a prática docente. Ou seja, procura entender a elaboração do pensamento, as maneiras de explicar, além de compreender e executar a matemática dentro do contexto sociocultural do indivíduo partindo da realidade para o pedagógico de forma natural, valorizando o saber advindo do fazer e procurando utilizá-los para potencializar o ensino e aprendizagem matemática. $O$ ensino matemático não pode ser concebido em uma perspectiva unilateral, seguindo um paradigma totalitário corretamente construído, pois, nem sempre é coerente.

Existe um entrelace entre a Matemática científica, a Matemática escolar e outros saberes matemáticos que são assumidos pela etnomatemática. Assim, fica explicito que a concepção pautada em concepções tradicionais, não admite quaisquer saberes que não estejam de acordo com o seu. Por conseguinte, tanto a Matemática escolar como os outros saberes matemáticos só fazem sentido se estabelecer uma relação com a Matemática científica, seja esta relação uma comparação ou relação de hierarquia. Vale salientar que "a etnomatemática privilegia o raciocínio qualitativo" (D’AMBRÓSIO, 2002, p. 44).

O conhecimento matemático acontece entre contrastes: o concreto e o abstrato, o redondo e o quadrado, o particular e o geral, o côncavo e o convexo, o formal e o informal, o finito e o infinito, o discreto e o contínuo. Essa dualidade serve de fascínio ou de obstáculo na aquisição dos conteúdos da Matemática, que se constitui uma valorosa área de estudo, pois abrange a resolução de problemas cotidianos; interfere no processo de estruturação do pensamento, do raciocínio lógico e serve de base para a formação de diversas capacidades.

\title{
Desafios e Implicações na Avaliação da Aprendizagem da Matemática
}


Diante da incontestável importância da aprendizagem da matemática é de grande relevância adentrar em uma das questões mais subjetivas do ensino: a avaliação. A forma de avaliar das escolas, muitas vezes está alicerçada em práticas pretéritas e não acompanham as mudanças decorrentes das demandas sociais. Mesmo defendendo uma avaliação processual, que transcenda as limitações de uma simples verificação quantitativa, com fim em si mesmo, é importante validar que existe espaço para a medida da aprendizagem dentro do processo de avaliação, desde que a sua utilidade esteja explícita e a sua finalidade não seja a exclusão.

No que diz respeito a avaliação pode-se afirmar que avaliar é sempre um tema muito polêmico, as opiniões se apresentam de modo diferente e educadores interessados em metodologias e instrumentos avaliativos mais dinâmicos e coerentes de avaliação deparam-se com a tradicional avaliação através de teste e prova escrita. Nos dias atuais são grandes as discussões e estudos sobre como avaliar os conhecimentos em matemática de uma maneira mais justa e que realmente apresente resultados significativos numa avaliação. Ou seja uma estratégia de avaliação dinâmica e:

Tendo em atenção que os objectivos curriculares incluem competências nos
domínios dos conhecimentos, capacidades, atitudes e valores, os
professores devem procurar encontrar formas diversificadas de recolha de
dados para a avaliação dos alunos, recorrendo, para além dos testes, a
relatórios e outros trabalhos e a desempenhos orais dos alunos e procurar
formas práticas e eficazes de registo desses dados de forma a viabilizar
uma avaliação formativa mais sistemática e a sua integração na avaliação
sumativa (APM ${ }^{3}, 1998$, p. 44)

A avaliação deve ser vista como um meio para a percepção, para o diagnóstico e para a análise de problemas no aprendizado e não apenas para comprovar dados, ou mesmo assumir um caráter seletivo, autoritário e punitivo.

A tradicional prova escrita tem suas vantagens, mas também pouco a expressar sobre os reais conhecimentos do discente. Pois o que deve ser primordial é o crescimento do aluno, seus progressos, a superação de suas dificuldades e o interesse que ele apresentou.

3 Associação de Professores de Matemática é uma associação de professores ligados ao ensino da Matemática, preocupados em discutir concepções e novo entendimento daquilo que deve ser valorizados na disciplina de matemática. 
A escola, de forma equivocada, pode utilizar a avaliação, principalmente a de matemática, como instrumento de coerção, por ser classificatória e seletiva e, muitas vezes serve para legitimar o fracasso e reduzir a autoestima dos estudantes ditos normais e concomitantemente inflar o ego daqueles que se julgam superiores por compreender a matéria. Em uma proposta de educação democrática e inclusiva, não existe espaço para tais práticas.

A subjetividade da avaliação faz com que esta, às vezes, esteja mais a serviço da expectativa do professor, que do desenvolvimento potencial do estudante, pois:

\begin{abstract}
É importante saber que muitas são as forças que interferem diretamente no processo de avaliar. Algumas delas são: a forma como pensamos a inteligência, a concepção de conhecimento, a relação da escola com a família, as condições do professor e a didática que ele utiliza (SMOLE et.al., 2004, p. 19).
\end{abstract}

A quantificação da avaliação deve ser objeto de reflexão do professor, que deverá ter bem definido o objetivo desta ação. A inteligência humana é complexa e vai muito além da capacidade de memorização, que muitas vezes é o único aspecto avaliado em detrimento das construções individuais. O objetivo de avaliar é possibilitar ao professor uma visão clara sobre as intervenções que devem ser feitas para o crescimento do aluno. Avaliar é o ponto de partida do professor, a base da tomada de decisões, e a avaliação deve ser diagnosticada sempre em função do contexto e da intencionalidade (LOPES, 2007).

A avaliação é funcional, sistemática, processual e integral e deve sempre estar a serviço da aquisição do conhecimento e jamais da marginalização do educando. É funcional, por ser um instrumento utilizado para alcançar determinados objetivos; sistemática porque deve ser organizada e planejada; processual porque é imediata e constantemente ressignificada; e integral porque vai além dos aspectos cognitivos.

A exclusão não deve ocorrer, mas será inclusão promover para o exigente mundo que existe fora da esfera escolar um aluno que não possa competir com outro que desenvolveu mais competências? Será que é excluir, retirar da lista os analfabetos funcionais aqueles que sempre serão os mais lastimosos dados estatísticos? È importante pensar não simplesmente em avaliação excludente, mas sim em educação excludente. 
Por isso, a discussão sobre a avaliação adequada e de qualidade deve sempre ser precedida pela busca de uma educação inclusiva e equitativa.

A reflexão-ação sobre a arte de educar requer um olhar de amor, como de um artista na elaboração de uma obra prima, pois:

A educação é um ato de amor, sentimento em que homens e mulheres vêem-se como seres inacabados e, portanto, receptivos para aprender, sendo que não há diálogo [...]. Sendo fundamento do diálogo, o amor é, também, diálogo (FREIRE, 1987, p. 79-80).

É indispensável um constante diálogo reflexivo sobre o processo avaliativo, nos seus instrumentos, que vise transformações, as quais não sejam apenas para mudar a localização e a nomenclatura do mesmo. Uma boa avaliação requer uma prática educativa que desenvolva no educando independência, criticidade e autonomia para pensar, aprender, fazer, enfim, ser.

Dentre os diferentes instrumentos de avaliação, tem o portifólio que é uma modalidade que favorece não apenas a avaliação do conteúdo, mas principalmente a auto avaliação e o desenvolvimento da autonomia, devido as possibilidades de folhear o trabalho, escrever reflexões e retornar a ele sempre que necessário (SMOLE, 2004).

Discorrer sobre avaliação exige a exposição de um tema muito temido pelos alunos em matemática que é a correção porque mostrar ao professor uma atividade ou aguardar a quantificação de um exame causa ansiedade na maioria dos educandos. Submeter a produção e os saberes pessoais à apreciação de outrem mantendo o equilíbrio exige construções pessoais muito bem orientadas. $\mathrm{Na}$ história educacional da criança prepará-la para lidar ou não com situações como estas, que são corriqueiras da vida são muito utilizadas, principalmente para fins empregatícios.

Identificar o motivo do erro é essencial para o planejamento de ações positivas nas articulações necessárias para a aquisição do conhecimento matemático. Quando o erro não recebe o tratamento adequado, é provável que a situação não seja revertida. A utilização da avaliação com o objetivo de mediar as relações entre o saber construído e os que estão em construção, é indispensável a análise das produções, pois esta permite checar as hipóteses dos alunos e redirecionar a prática educativa de forma que favoreça a aprendizagem, utilizando o erro como mola propulsora na assimilação do conteúdo. E para tal trabalho 
desafiador e dinâmico o docente possui um papel de suma importância e deve estar sempre buscando atualizar-se para fazer a diferença, porque:

É fundamental que os resultados expressos pelos instrumentos de avaliação, sejam eles provas, trabalhos, registros das atitudes dos alunos, forneçam ao professor informações sobre as competências de cada aluno em resolver problemas, em utilizar a linguagem matemática adequadamente para comunicar suas idéias, em desenvolver raciocínios e análises e em integrar todos esses aspectos ao seu conhecimento matemático (BRASIL, 1998, p. 54).

Faz-se necessário ter consciência da complexidade das ações sugeridas para o profissional docente que foi formado em um contexto cartesiano e regulador. $A$ avaliação em uma perspectiva etnomatemática deve considerar a diversidade cultural em sua elaboração, no sentido de:

Propor uma reflexão voltada à elaboração de questões que sirvam de parâmetros para aproximar o convívio social, cultural e econômico de nossos alunos e com isso elaborarmos questões de matemática, levando-se em conta, sempre que possível, a realidade desses alunos (PEREIRA, 2012, p. 2).

É primordial que o professor desenvolva o pensamento crítico e reflexivo, a disposição à pesquisa, o conhecimento das diversas possibilidades avaliativas, o apreço pelo diálogo aberto e esteja imerso em programas de formação continuada para fortalecer seus conhecimentos pedagógicos, além de conhecer a cultura onde 0 estudante está inserido.

\section{Considerações Finais}

O desafio do professor se amplia ao refletir sobre a facilidade dos estudantes para acessar os avanços tecnológicos que realizam cálculos. Ter clareza de suas próprias concepções sobre a Matemática pode ajudar o professor a tomar decisões importantes para o processo de ensino e da avaliação, uma vez que a prática em sala de aula, as escolhas pedagógicas, a definição de objetivos e conteúdo de ensino ,as formas e os instrumentos de avaliação, estão intimamente ligadas a essas concepções.

Ao chegar à escola, o aluno traz um vasto legado de vivências matemáticas, mesmo sem ter consciência de que está se comunicando e compreendendo o mundo através desta linguagem universal. Via de regra, na vida cotidiana, o 
educando estabelece contato com vivências matemáticas, muitas vezes tendo como referencial o próprio corpo. O professor deve potencializar estes conhecimentos, utilizando-os como referência para o ensino formal, reconhecendo e aplicando em sua prática os multiletramentos.

Avaliar requer dados e a coleta dos mesmos poderá ser efetuada através de diferentes possibilidades, que dependerá do foco do professor para o momento. Pois redirecionar o olhar; ver o aluno como um ser apto para adquirir conhecimento; enxergar os avanços; perceber as intervenções necessárias; registrar e analisar com criticidade é vital para a avaliação docente.

As vivências matemáticas fazem parte do cotidiano de todos. Sendo assim éimprescindível manter um olhar sensível ao conhecimento matemático produzido na comunidade e validar o erro como parte do processo de aprendizagem propiciando uma relação agradável, lúdica e afetiva entre a linguagem matemática e os estudantes durante o processo de alfabetização são ações eficientes para a aprendizagem matemática.

\section{Referências}

ALMEIDA, S. C. Dificuldades de aprendizagem em Matemática e a percepção dos professores em relação a fatores associados ao insucesso nesta área. Brasília: UCB, 2006.

Associação de Professores de Matemática. Recomendações para o ensino e aprendizagem da Matemática. Lisboa: Associação de Professores de Matemática \& Instituto de Inovação Educacional, 1998.

BRASIL. Parâmetros Curriculares Nacionais: Matemática. Secretaria de Educação Fundamental. Brasília: MEC/SEF, 1997.

BRASIL. Secretaria de Educação Fundamental. Parâmetros Curriculares Nacionais: terceiro e quarto ciclos do ensino fundamental. Matemática. Brasília: MEC/SEF, 1998

D'AMBRÓSIO, U. Etnomatemática: elo entre as tradições e a modernidade. 2. Ed.. Belo Horizonte: Autêntica, 2002.

D'AMBROSIO, U. Sociedade, cultura, matemática e seu ensino. São Paulo: Educação e Pesquisa, 2005.

FREIRE, Paulo. Pedagogia do Oprimido. 17. ed. Rio de Janeiro: Paz e Terra, 1987.

FREIRE, Paulo. Pedagogia da Autonomia: saberes necessários à prática educativa. Rio de Janeiro: Paz e Terra, 2011. 
KARLSON, P. A magia dos números. Rio de Janeiro: Globo,1961.

LOPES, B. J. S. O mapa conceitual como ferramenta avaliativa. Londrina: [material impressso] 2007.

PEREIRA, J. C.S. A Etnomatemática No Processo Avaliativo da Aprendizagem da Matemática Escolar. Educação, Cultura e Matemática na Escols. UFPA, 2012.

SMOLE, K. C. S. et al. Era uma vez na matemática: uma conexão com a literatura infantil. São Paulo: CAEM/IME/USP. 2004,

TOLEDO, A. M. Educação Popular na Escola Pública. São Paulo: Cortez, 2009.

SOUZA, M. J. A. Informática Educativa na Educação Matemática: Estudo de geometria no ambiente do Software Cabri-Géomètre. Fortaleza: UFC 2001 